\title{
Anomalous Origin of Left Pulmonary Artery From Ascending Aorta: Embryological Model
}

\author{
Bin $\mathrm{Li}^{1}$, Aijun Liu ${ }^{1}$, Ming Yang${ }^{1}$, and Junwu $\mathrm{Su}^{1}$ \\ ${ }^{1}$ Capital Medical University Affiliated Anzhen Hospital
}

October 16, 2021

\begin{abstract}
Background Anomalous origin of the left pulmonary artery (ALPA) from the ascending aorta (AA) is a rare congenital heart malformation. Aim To give some of our embryological considerations of ALPA from the AA. Methods We present a patient with ALPA from the AA, right-sided aortic arch, right-sided ductus arteriosus (DA), and aberrant left subclavian artery (LSCA). Results The distal end of ALPA was cut off, the proximal end was sutured, and the distal end was directly anastomosed to the left wall of the main pulmonary artery (MPA). Conclusion The failure of migration and differentiation of cardiac neural crest cells at the fourth and sixth archs result in unilateral arch agenesis or failure of detachment of the left sixth arch from the aortic sac, which form ALPA the AA.
\end{abstract}

\section{Hosted file}

Manuscript.doc available at https://authorea.com/users/374181/articles/541912-anomalousorigin-of-left-pulmonary-artery-from-ascending-aorta-embryological-model 


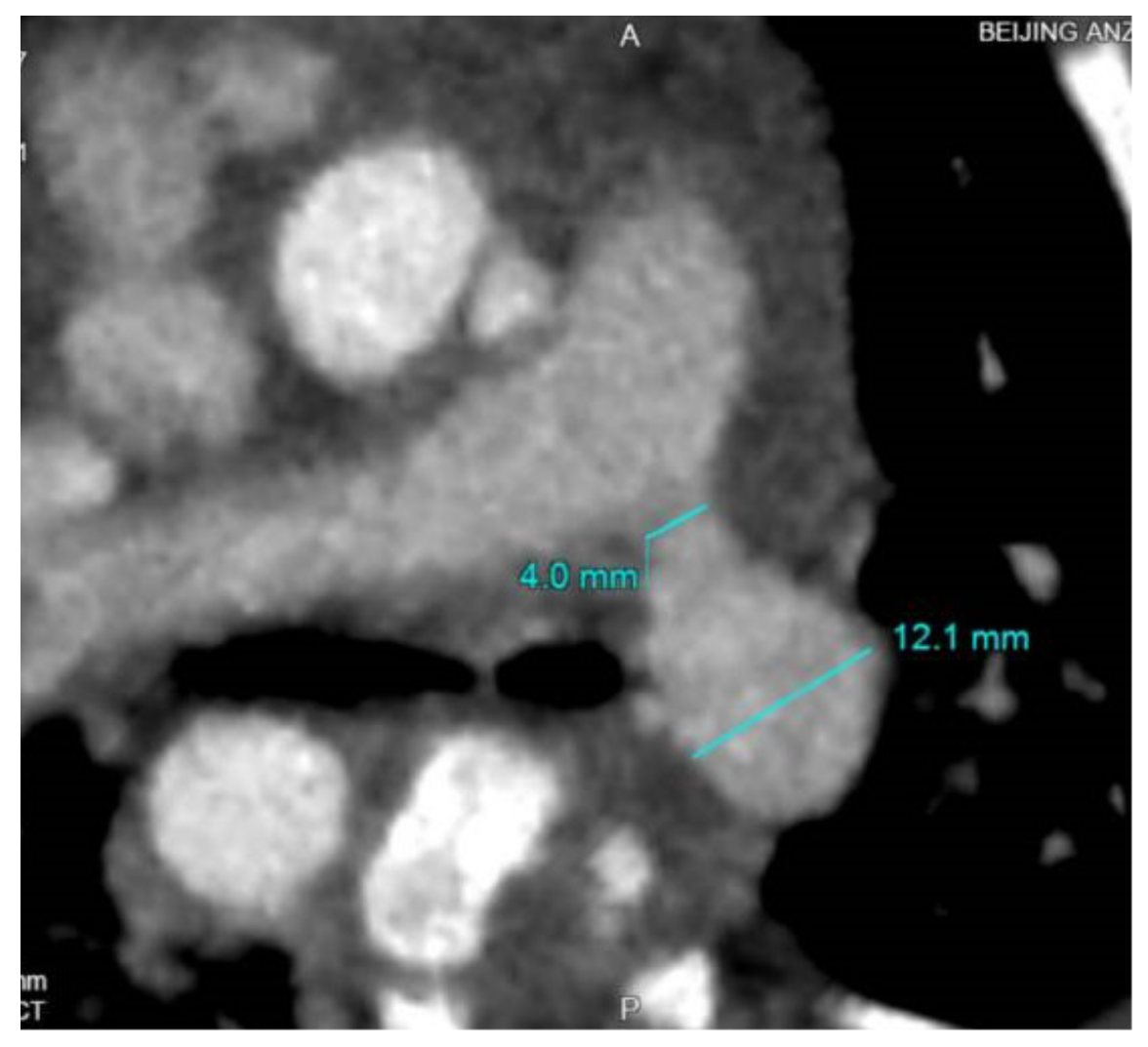




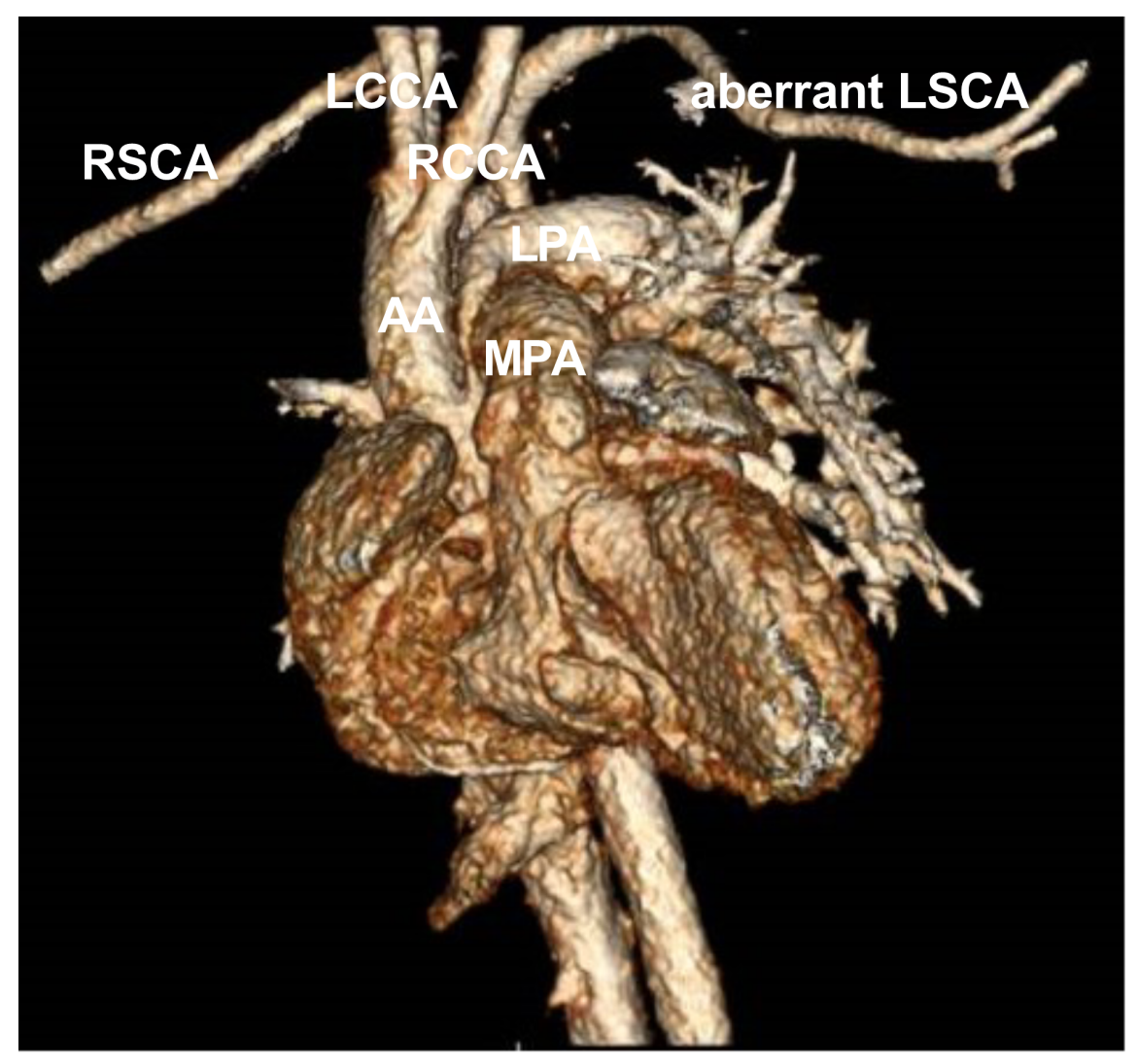




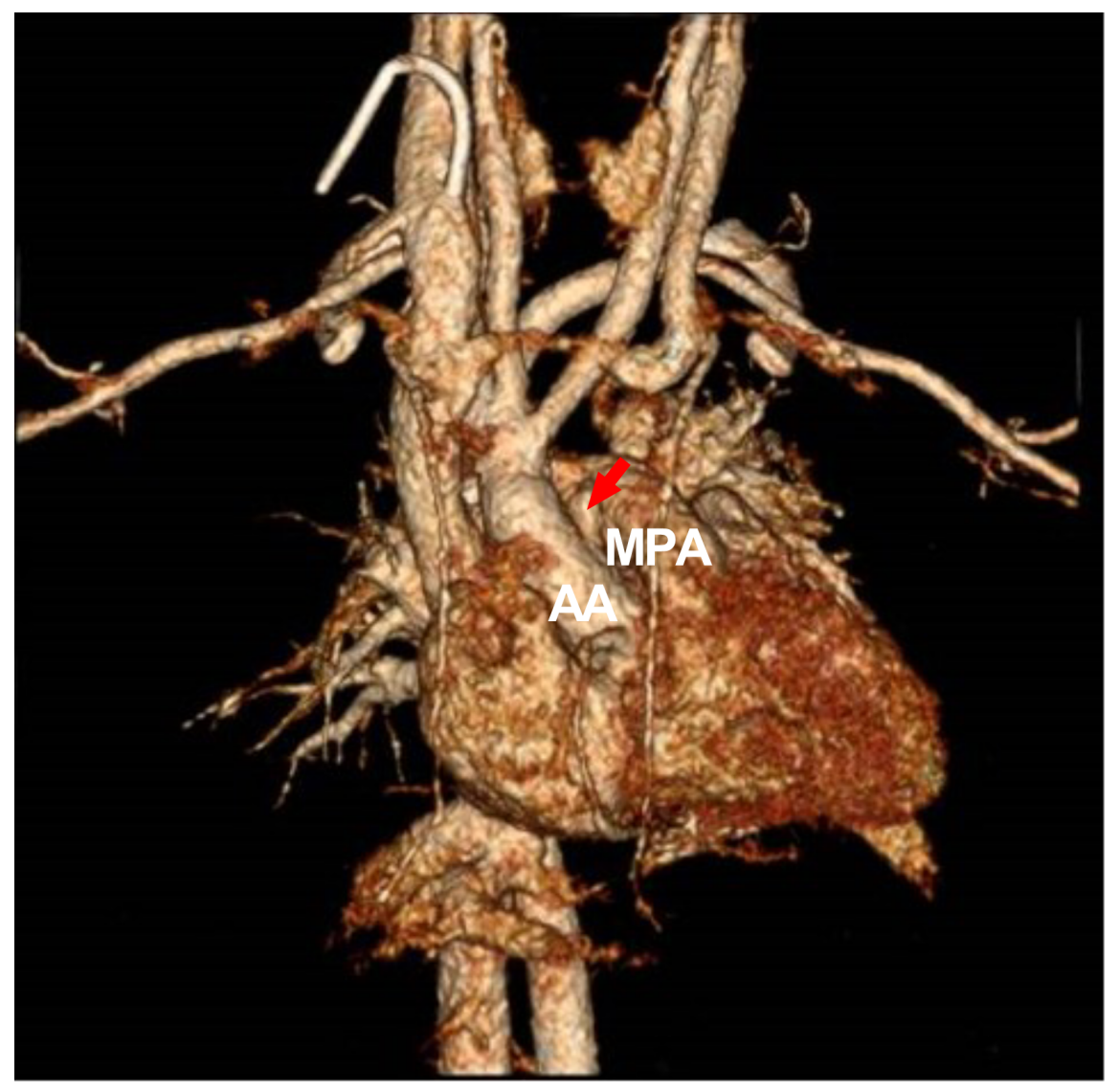



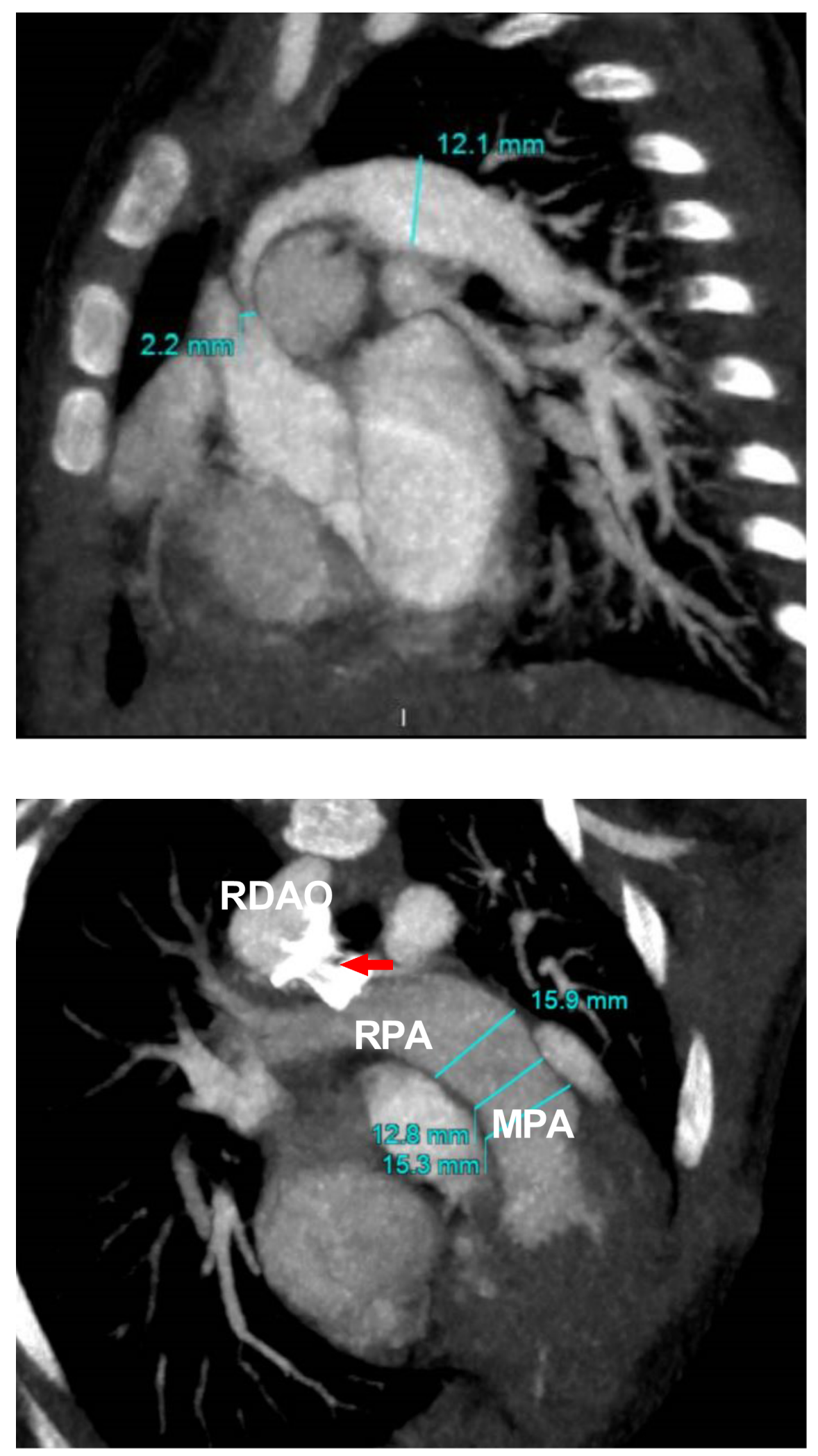